\title{
On Characteristics of Tang Legend The Tale of Li Wa
}

\author{
Wenmin Chen ${ }^{1}$ \\ ${ }^{1}$ College of Literature and Journalism, Sichuan University, Chengdu, Sichuan Province, China
}

Keywords: Tang Legend; The Tale of Li Wa; characteristics.

\begin{abstract}
Tang Legend is a kind of novel created by scholars. Legends on love stories are most fantastic and can represent the outstanding achievements of Tang Legend. The Tale of Li Wa written by Xing-jian Bai tells a moving love story between Li Wa, a courtesan and Student Zheng, a well-born tribute student. The Tale of $\mathrm{Li} \mathrm{Wa}$ has its own distinctive features from four aspects, including the pure love story, description of strange affairs and real events, and the happy ending.
\end{abstract}

\section{Introduction}

The Tale of Li Wa written by Xing-jian Bai is a classical work of Tang Legend, and has a space in the history of literature. It adds a vivid color to the colorful literature of Tang dynasty. The Tale of Li Wa tells the story between Li Wa, a famous courtesan and Student Zheng, a well born tribute student. It is the earliest work which praise and extol courtesans in lower social status, and is known as "one of the three greatest Tang legends of love". Xun Lu once said: "Xing-jian is at good writing, while the story of $\mathrm{Li} \mathrm{Wa}$ is reasonable and uncommon, so the tale is pretty intriguing." [1] The distinctive features of The Tale of Li Wa are as follows.

\section{The Tale of Li Wa Depicts a Pure Love Story between the Scholar and Courtesan}

The Tale of Li Wa get rid of the influences of prevailing absurd novels which tend to describe ghosts and gobs. It depicts a pure love story between a scholar and a courtesan. Compared with other legends, The Tale of Li Wa is not as absurd as legends written in Early Tang Dynasty, nor satirical as historical novels which set people thinking. It does not represent characters who have strong sense of justice and ready to help the weak like chivalrous novels, but the moving human feelings in the story can impress readers deeply. Compared with other love legends, The Tale of Li Wa also has distinctions. The Tale of Liu Yi written by Zhao-wei Li tells a love story between a scholar and a dragon lady. Supernatural spirits can be found in the book easily. The Tale of Huo Xiao-yu tells a love story between a scholar and a courtesan, but the thought on ghosts and gods is permeated in the text. The Tale of Li Wa depicts a pure love story between a human scholar and a human courtesan. There's no supernatural phenomena or absurd atmosphere in the book, but readers can enjoy a love story which is full of twists and turns. The two lovers have special identities. Student Zheng is the only son of a respected high official, while Li Wa is a famous courtesan in Chang'an. They experience all kinds of joys and sorrows, separations and unions. In brothels, some courtesans pursue for money, while others are fond of talented scholars. Student Zheng is young, handsome, elegant and talented. Let alone he is the son of a government official, and was born in a pretty rich family. Li Wa is attracted by him naturally. Her affection is the beginning of their marriage. Although their relationship starts in a vanity fair, the inevitable impurity lays the foundation for their pure love. When reads these lines, most readers sigh with emotions.

\section{The Tale of Li Wa Describes Four Wonders}

Although The Tale of Li Wa depicts a pure love story between a human scholar and a courtesan, it still belongs to Tang Legend. Legend, as the name implies, describe miracles and uncommon things. Thus, wonders in the book become distinctive features of The Tale of $\mathrm{Li} \mathrm{Wa}$. The four most representative wonders are as follows. 
Firstly, as a courtesan in Chang'an, Li Wa is conferred as the "Lady of Qianguo" and receives highly respects. It is really an unheard-of fantastic story. Mentioned courtesans, people have to admit that their fates are unfortunate. It is difficult for them to get married, since social ethics reject them from doing that. "Since they come from the brothel, most literati families do not allow them to get married with their son as the principal wife. Some families even do allow them to become a concubine. Although the affection between scholars and courtesans are sincere and passionate, their relationships often become tricky when they want to get married. Many scholars cannot oppose the decision of their parents, or sacrifice their political future and personal reputations. In the conflict between true love and practical interests, the idealistic and romantic love is what they discarded" [2]. But things are different in The Tale of Li Wa. Li Wa not only enjoys the treatment of a principal wife, but also be conferred as the "Lady of Qianguo" and get highly social status.

Secondly, the plot of The Tale of Li Wa is dramatic and full of twists and turns. The author describes ups and downs in the life of Student Zheng in detail. After Zheng spends all of his money and can no longer pay the prostitution costs, Li Wa abandons him, as does the bawd. Student Zheng falls directly into the bottom of the reality and suffers physically and mentally. Then he begins working at a funeral parlor as a dirge singer and at one point is the winner of a singing competition. The student's father discovers him while visiting Chang'an and severely beats him, as he is upset that his son is in this condition. The father leaves the son for dead, disowning him. Later Li Wa encounters the protagonist, who is now a beggar. She helps him recover his health, study for the examinations, and reconcile with his father. The father exclaims that he and his son are "father and son as before" when they reconcile. Student Zheng is firstly abandoned by Li Wa, then by his father; after that he is rescued by Li Wa, and reconciled with his Father. He falls in the dumps where are full of darkness, then reaches the peak of his life, getting fame and affection. The great disparity amazes the readers.

Thirdly, in order to abandon Student Zheng, an extraordinary ingenious scam is created. The scam is really rare to be seen. From Zheng's initial preparation of sacrificial animals and sweet wine, to his return of the aunt's residence and find there's no one in the house, the whole process is so carefully and precisely arranged that no one can found any flaws in it. Without knowing beforehand, outsides would also be fooled. After discovering the truth, Student Zheng is shock, anger, resent and refuse to eat anything. This is the situation of heartbreak and abandonment by those you love. Some people even cannot bear to hear that. In this treacherous scam, everyone successfully played their part. The plan is a mixture of truth and falsehood, and is difficult to be told.

Fourth, in order to show Li Wa's filial piety in marriage, two miracles appear in the novel: Ganoderma lucidum and white swallows in their houses. Ganoderma lucidum is precious and rare, while white swallows are symbol of good fortune. It is not surprising that officials report the emperor to the miracle of Ganoderma lucidum. The author uses these miracles to extol Li Wa's filial piety, hardworking, competent and chastity in family life, and correspond with the description of "her virtues and deeds are commendable" at the beginning of this novel. Certainly, there are other wonders in The Tale of Li Wa, such as Li Wa and Student Zheng's reunion on the wall and horseback, the Duke of Xingyang beat his son to death for saving face, then seek reconcile with his son after the young man successful make rapid advances in his career. All these wonders greatly widen readers' horizons.

\section{The Tale of Li Wa Describes Sincere Feelings and Real Events}

As a legend, The Tale of Li Wa depicts some wonders. But at the same time, some real events and feelings are also included in the book. The complexity of Li Wa's thoughts emphases the sense of reality and truth, which can be seen in her change from abandoning Student Zheng to accepting Student Zheng again. In the scam, although Li Wa has affection towards Student Zheng, she has to obey to the arrangement of the bawd. When he meet Student Zheng again, the handsome young man has become a miserable beggar. At this point, Li Wa's kindness is evoked. She persuades the bawd and buys back her freedom, then takes care of Student Zheng and encourages him to take on the final imperial examination. Finally she receives reward, Student Zheng regains fame and position. In this process, Li Wa affords for their food and clothing, supports his study and subsidizes him to take 
the test. All these things are based on her true love. From abandonment to reconciliation, from pursuing interests to real feelings, the author shows the complexity of Li Wa's thought. "The author creates characters according to real life, and develops well-rounded characters as actual flesh-and-blood human beings." [3] Li Wa is a positive character, but she is not perfect. From the starting point of life, the author seizes her contradictory personalities out of the complexity of her growth environment. Thus, the image of $\mathrm{Li} \mathrm{Wa}$ become is convincing. Sometimes $\mathrm{Li} \mathrm{Wa}$ is chasing profit and only cares about practical interests, while sometimes she shows humanity and true emotions. The image is quite vivid and unique.

In addition, The Tale of Li Wa is fictional, but the author tells it like a true story, and tries to make people believe that it is true. In the opening of the novel he points out: "Lady of Qianguo, whose name is $\mathrm{Li} \mathrm{Wa}$, is a courtesan of Chang'an. Magnificent and rare, her virtues and deeds are commendable. Imperial Inspector Xing-jian Bai thus notes her life." The author not only mentions the identity of Li $\mathrm{Wa}$, but also explains why he wants to notes her life. Then he describes the family background of Student Zheng. "During the Tianbao Era, the Governor of Changzhou is the Duke of Xingyang. He enjoys very high esteem at the time and had multiple servants. At the age of 50, he has a son. When the young man turns 20, he is handsome and eloquent, a far cut above the average, and deeply respected by his contemporaries." Reading these lines, a young, handsome and elegant scholar is show in front of readers. In the end of the novel, the author emphasizes the authenticity of the story again. He says that his great aunt takes the same position with Student Zheng, so he knows this story in detail. He emphasizes that the source of the story is very reliable. From the beginning to the end, the author always stresses, the story of The Tale of Li Wa is true. But readers know that in Tang Dynasty, this story could not really happen. Why the author chooses to tell the story in this way? Perhaps because at that time, history documents are very important. Under that situation, novel writers tend to learn from historiographers, and emphasize the authenticity of stories.

\section{The Happy Ending of The Tale of Li Wa}

In the Tang and Five Dynasties, most novels on the relationship and marriage between scholars and courtesans have tragic ends. Take the famous love legend The Tale of Huo Xiao-yu which was written at the same time as an example. A courtesan named Xiao-yu Huo fall in love with Yi Li, but the man is heartless and break up with her. Huo fall ill for a long time. After seeing Li for the last time, Huo departs and become a ferocious ghost, haunting $\mathrm{Li}$ as well as his wife and concubines. This is a tragedy of human love. But The Tale of Li Wa is different; it has a happy ending. Li Wa and Student Zheng live happily with glory, splendor, wealth and rank. The happy ending is another major feature of the book.

First of all, the happy ending reflects the traditional preference that Chinese people wish all lovers can get married. Since ancient times, Chinese people have been pursuing persistent love, hoping good people can have happy endings. If some couples can not get married in real life, they can choose to be together after death, just like the traditional story of "butterfly lovers". Even though the love between Shan-bo Liang and Ying-tai Zhu is not approved by their parents, the ending of them is quite popular and moving. There are many popular poems on the pursuit of love, such as the quotes written by Ju-yi Bai in Everlasting Regret: "that we wish, to be the inseparable birds flying in the heaven, and the joint branches of one tree growing on the earth." The happy ending of The Tale of Li Wa reflects this traditional preference. "Love between the courtesans and scholar is sincere and beautiful, but courtesans are in lower social status, and their marriage is prohibited by the law at that time. Thus, the majority of them are victims of feudal hierarchy system. Therefore, the happy ending of the love affair between Li Wa and Student Zheng is impossible in real life at that time." [4] Although in Tang and Five Dynasties, love between scholars and courtesans could not end up well, and the happy ending of The Tale of Li Wa is not realistic, it conveys people's good wishes towards love, and their hopes of living happy lives.

Secondly, the happy ending of The Tale of Li Wa expresses strong dissatisfaction against the feudal hierarchy system. Laws of the Tang Dynasty define the boundaries of social classes, and stipulate that people from different classes are not allowed to get married. The strict marriage system 
not only suppresses people's normal emotions, but also causes their strong dissatisfaction. As a courtesan, Li Wa is in lower social status. From the social reality of that time, she could not be the wife of a high-rank official. But Student Zheng, the son of the Duke of Xingyang, loves her from the beginning to the end. While his father, a representative of the feudal hierarchy system, does not mind the identity of $\mathrm{Li} \mathrm{Wa}$, and supports their marriage. After getting married, Li Wa is filial piety, hardworking, competent and chastity in family life. She receives highly respects, and is conferred as the "Lady of Qianguo" by the emperor. These uncommon affairs correspond with the description of "her virtues and deeds are commendable" at the beginning of this novel. Author Xing-jian Bai depicts Li Wa as a character who defeats the feudal hierarchy system. He uses this comedy to ridicule, satire and criticize the feudal hierarchy system, and to express strong dissatisfaction against the unreasonable system and the feudal ethics in real life.

The Tale of Li Wa written by Xing-jian Bai depicts a love story. As one of the "three greatest Tang legends of love", it brings now color to literature of Tang dynasty. The story is fascinating, attractive and with distinctive features, some patterns and scenes in the novel also provide example for future generations. It has great influences on later novels and dramas.

\section{References}

[1] X. Lu, A Brief History of Chinese Novels, Shanghai Classics Publishing House, Shanghai, 2004.

[2] Q. Chen, N.B. Dong, The Spiritual Civilization of Tang Empire, China Social Sciences Publishing House, Beijing, 1996.

[3]X.S. Zhou, Appreciation of Classical Novels, Peking University Publishing House, Beijing, 1992.

[4] J. Lin, Analysis on the happy ending of The Tale of Li Wa, J. Journal of Tongren Teachers College. 04 (2004). 